\title{
Research on Group Cooperative Learning in Linear Algebra Teaching
} Qi Liu*

School of Mathematics and Statistics, Anyang Normal University, Anyang, China

DOI: $\underline{10.36348 / \mathrm{jaep} .2019 . \mathrm{v} 03 \mathrm{i} 11.006}$

| Received: 20.11.2019 | Accepted: 27.11.2019 | Published: 30.11.2019

*Corresponding author: Qi Liu

\section{Abstract}

Introduction: Group cooperative learning is a new teaching method, which makes the traditional, single and passive teaching methods become new, diverse and active teaching methods, and the teaching contents and teaching process are also from presupposition and closure to generation and openness. Such teaching methods can better cultivate students' innovative spirit and practical ability. This paper introduces the group cooperative learning mode into the teaching of linear algebra class, through teaching practice and investigation and research, we find some problems in the process of advancing, and think positively about these problems, and give effective solutions, which can provide a powerful guarantee for the wide application of group cooperative learning.

Keywords: Group cooperative learning, Linear algebra, Group division, Evaluation mechanism.

Copyright @ 2019: This is an open-access article distributed under the terms of the Creative Commons Attribution license which permits unrestricted use, distribution, and reproduction in any medium for non-commercial use (NonCommercial, or CC-BY-NC) provided the original author and sources are credited.

\section{INTRODUCTION}

Linear algebra is an important branch of mathematics. It is a basic compulsory course for majors in science and engineering and economic management in higher education institutions. It is part of the subject of the entrance examination for postgraduate students. Therefore, it has always been a department of colleges and universities. In basic mathematics, learning linear algebra is very important for college students. However, due to the many concepts, logic and abstract content of this course, students will find it difficult, boring and difficult to adhere to during the learning process. In order to solve this problem, I tried to apply the group cooperative learning mode in two classes of 2017 accounting courses in our school and achieved certain results.

The group cooperative learning is a groupbased teaching form. It is a teaching method based on the traditional teaching mode. Under the premise of recognizing classroom teaching as the basic teaching organization form, the teacher uses the student study group as the teaching method. The important teaching organization means through the cooperation of the guiding group members to form a learning mode of "intra-group member cooperation and inter-group member competition"[1]. The group cooperative learning is different from the current teaching mode of most colleges and universities in China. Throughout the practice teaching process, I deeply understand the advantages of the group cooperative learning, the problems existing at the current stage, and how to make the group cooperative learning really play its huge role in the teaching process through adjustment.

\section{RESULTS AND FINDINGS \\ The Advantages of Group Cooperative Learning}

The original meaning of the group cooperative learning is not only to learn knowledge, but more importantly, to enable students to analyze, summarize, deduct and other thinking methods in the process of discussion and learning, to improve students' ability to use the knowledge they have learned to analyze and solve problems. Through long-term investigation and research, it is found that the group cooperative learning mode can fully mobilize the students' enthusiasm for learning and the ability to unite and cooperate [2]. It has its own unique advantages compared with traditional teaching, as follows:

(1) The group cooperative learning changes passive learning to active learning. The group cooperative learning usually organizes teaching in the form of questions and guides students to organize and manage learning problems. Therefore, the purpose of the group cooperative learning is to organize students' discussion in the form of "groups". In modern educational theory, students' autonomous learning and student-oriented learning are emphasized. This is fully taken into account in the group cooperative learning, so 
that every student can participate and become the main body of learning.

(2) The group cooperative learning strengthens the team spirit and urges the study to each other. The group cooperative learning, in a sense, gives students a chance to work as a team. In class discussions and afterschool preparation, they can fully appreciate that completing any topic is not a one-time process, nor is it a manifestation of individual will. Only by brainstorming and sharing, in the attitude of common progress, can the task be completed quickly and well. Usually, the top students are the first masters of knowledge, and the prophets are the teachers. These students have the best understanding of the group's underachievers. For the group's collective interests, they are often willing to sacrifice some of their time, and the group has the targeted deployment of one-toone help. At the same time, they also deepen the understanding of knowledge, and also exercise the expression ability [3].

(3) The group cooperative learning improves students' learning ability [4]. Group cooperative learning is not only to learn knowledge, but more importantly, to enable students to learn, analyze, summarize, interpret and other thinking methods in the process of discussion and in the process of learning, to improve the overall quality of students' use of knowledge to solve problems.

\section{The Problems of Group Cooperative Learning}

Table-1: The Problems of Group Learning

\begin{tabular}{|l|c|}
\hline Currently Existing Problems & Statistics \\
\hline Teachers' control work should be strengthened & 5 \\
\hline Group division is not scientific & 12 \\
\hline Cooperation rules are not clear & 12 \\
\hline Limited class time & 15 \\
\hline Evaluation mechanism is not comprehensive & 11 \\
\hline
\end{tabular}

In order to clearly understand the students' adaptation to the group cooperative learning and timely discover the problems existing in the group cooperative learning, I conducted a questionnaire survey on 110 students in the first and second classes of accounting. A total of 55 questionnaires were distributed for each of the two students. A total of 55 questionnaires were distributed for each of the two students. Through investigation and research, it is found that the group cooperative learning model is not mature in the application process of linear algebra class, and there are some problems as follows:

(1) Teachers should strengthen the class control. Group cooperative learning is not to simplify the management work, but to put forward higher requirements for managers and teachers. Many teachers who try to use group learning will simply think, "As long as the group is divided, the students will manage themselves." The actual situation is often quite different. The students who started the group study were still unable to find a clue than the teachers. They may have the illusion that "teachers don't care about the class", so they don't concentrate on self-study, gossip in class discussions, or run questions when they are making speeches. This is due to group cooperative learning or a transition, no matter teachers; students are not clear about the nature of group cooperative learning [5]. In particular, teachers have no experience in organizing and guiding students to study independently discuss actively, fully arouse students' enthusiasm for learning, and guide students to carry out group learning, which needs to be improved. Teachers' timely points, inspiration and participation in the process of discussion are of positive significance to promote the discussion.
Interrupting the discussion, students feel that there is nothing to discuss and other phenomena are often encountered in the implementation of group teaching problems. How can the students carry out the discussion smoothly? How to continue the discussion in depth after the student discussion is interrupted? This is the most basic part of teacher implementation group cooperative learning. Teachers are guides and actual operators in group cooperative learning. There is no doubt that improving teachers' awareness of cooperation and control ability will be the key to this reform, and it is also a key point that must be solved.

(2) Group division is not scientific. The division of the group in cooperative learning is a key part of the implementation of this teaching model, and plays a decisive role in the teaching effect of the group teaching. The common problems that exist in group division now are:

A) Team members have an uneven ability. In the division of the group, the comprehensive ability of academic performance, ability level and language expression was not comprehensively considered, resulting in uneven team members. The balance of strength of each group means that each group should have a certain number of top and bottom students, which is conducive to the discussion of the group, which is conducive to mutual help and in-depth interaction between students, and is conducive to mobilizing their enthusiasm and independent learning ability, and group's competition.

B) The gender ratio of the group is not balanced, and the number of boys and girls in the same 
study group should be balanced. Since I just took over the new class and didn't know much about the students, I combined the group according to the students' own wishes, resulting in a group of boys and boys, a group of girls and girls. Some groups were too silent, and some groups were too active.

(3) The rules of cooperation are not clear. In the class, this phenomenon often occurs. After the teacher asks a question, the students will immediately discuss it. There will be a lively discussion in the classroom. But as long as you pay attention to it, it is not difficult to find out. This is just a superficial "fake", actually "live and disorderly." Some groups always have only one or two people speaking. Others don't say a word, they just sit absent-mindedly; some groups deny each other and no one speaks; some groups take the opportunity to chat, laugh or do something else. The people are clouded. The reason is mainly due to the lack of rules for group cooperation. There is no rule. The members of group are not clear, cannot fully mobilize, and improve the enthusiasm of each team member.

(4) Class time is limited, the Effect is not good. In the group study, there are 15 minutes of self-study time, 10 minutes of discussion time, in general, time is limited, and the rest is the group exchange time with teachers and students. Students have limited comprehension and self-learning ability. Many times they barely complete the problem, but the effect is not good. It is not ideal. Therefore, how to use the spare time to fill the gaps in the class, this problem also needs to be resolved.

(5) Evaluation Mechanism is not comprehensive. After the group activities were carried out, the group conducted a class-wide report exchange, and then the teachers and students interacted, but many groups sent representatives to speak, often failing to reflect the success of the group discussion [6]. The main problems are as follows: First, it focuses on the evaluation of individual students, ignoring the evaluation of the group of students; secondly, it focuses on the evaluation of group cooperative learning results, ignoring the evaluation of learning processes and methods; thirdly, the attention to active students ignores those students who are usually introverted and speechless. This kind of unfair and incomplete evaluation is particularly easy to dampen the enthusiasm and initiative of students to participate in cooperative learning, and cannot give full play to the function of "evaluation for development".

\section{Measures to Improve the Effectiveness of Group Teaching}

Through the investigation of students and selfsummary, we found a series of problems in the group cooperative learning mode in linear algebra teaching. In order to make the group work together to truly serve the teaching and to carry out better development, I have given the following improvements to this series of questions:

(1) Giving full play to the teacher's control and guidance. The original meaning of group cooperative learning is not only to learn knowledge, but also to let students learn to analyze, summarize, summarize, deduct and other thinking methods in the process of discussion and in the process of learning, to improve the comprehensive quality of students using knowledge to solve problems. Therefore, "group teaching" must have problems worth discussing, and the difficulty of "problem" should be compatible with the students' knowledge, understanding, and thinking ability. There is a question worthy of attention here: the students have the knowledge and ability to solve the problem and the knowledge and ability to solve the problem. Scientifically demonstrate the feasibility of "discussion" and reasonably grasp the focus of "discussion" so that the slope of the problem is reasonable and the students learn to gain. This requires teachers to prepare courses in textbook analysis, academic analysis, and instructional design. It is not only for preparing teaching materials, but also for preparing students, and preparing for inspiration, inspiration, and participation in advance. Higher requirements are put forward for teachers: First, the knowledge reserve should be more profound, second, it must have a strong ability to play on the spot, and third, it must have a strong ability to analyze and summarize problems.

(2) Establish scientific groupings. Scientific grouping is conducive to arousing the enthusiasm of group members, enlivening classroom atmosphere, group communication, competition, full cultivation and improvement of students' autonomous learning ability.

The strength of each group should be balanced and appropriate. Balanced collocation can make everyone discuss; secondly, it helps students to help each other in depth and enhance their emotional experience; once again, they can effectively compete in the group.

The will of the team member should be respected. First give the students a month to adapt to the time, and then according to the students' wishes, free combination, but unreasonable, teachers should make appropriate adjustments, try to reflect fairness. Grouping and grouping should follow the principle of "homogeneity between groups, heterogeneity within groups, and complementary advantages". After the students have voluntarily combined, they will make appropriate adjustments based on their basic knowledge and personality. Complement each other's' strengths, help each other and achieve the best combination [7].

Choosing the right team leader. The group leader is the core role of a group, then the recorder, the spokesperson, but the recorder and the spokesperson can take turns in order to be fair. First of all, the group 
leader is the backbone and activist of this group, and has a good foundation in terms of knowledge and ability. Second, it has initial organizational capabilities. Once again, we can handle and coordinate the interpersonal relationships within the group. During the discussion, the group leader actively organized and fully mobilized the enthusiasm of the team members so that everyone could speak.

Reasonably arranging the classroom. Reasonable layout of classroom seats, square seats, 7-9 people in each group, can move once every two weeks, eliminate dead ends and expand the scope of interaction. Such an environment arrangement is conducive to cultivating students' team spirit and cooperation awareness, promoting student communication and social development, and forming an interactive competitive atmosphere.

(3) Establish an orderly cooperation rule. The group's cooperative learning has made the classroom atmosphere active. At the same time, teachers need to control the classroom order, prevent the dead, and suppress the excessive and chaotic situation. Therefore, it is very important to construct an orderly cooperation routine.

Reasonable division and clear responsibilities. The group has a team leader, a recorder and a spokesperson. In order to mobilize everyone's enthusiasm and show personal opportunities, the recorder and the spokesperson can take turns. The team leader fully organized the group members to conduct inquiry and communication. The recorder recorded the results and contents of the group discussion, while the speaker spoke on behalf of the group and communicated with other groups. Other members should actively discuss and cooperate, fully cooperate and play a team spirit.

Developing good cooperative learning habits. The first is the habit of independent thinking, to avoid the group's exchange of "people and clouds" blindly follow the crowd; the second is the habit of actively participating and actively speaking, to avoid unnecessary disputes and quarrels.

(4) Creating a relaxed learning atmosphere. Teachers should create a democratic, harmonious, relaxed and free learning atmosphere for group cooperative learning, respect and protect students' enthusiasm for participation, and encourage students in various forms, especially introverted and less-speaking students to actively participate in activities and fully mobilize the enthusiasm of every classmate. Teachers should be good at learning to encourage and magnify the strengths and strengths of students to motivate them to learn.
Provide ample time for cooperative learning. Generally, 15 minutes of self-study, 10 minutes of group discussion, 25-minute exchanges between teachers and students, relatively sufficient time. However, there is still less discussion time, which requires students to develop good habits before class, to reduce the time of self-study in the classroom, and to fully use the communication, inquiry and discussion [8].

(5) Adopting diverse evaluation and encouragement methods. Teacher evaluation plays an important role in motivating students to participate in activities and providing quality of cooperative learning. Therefore, teachers' evaluation must be encouraging, pertinent, guiding and comprehensive. First, attach importance to the combination of personal evaluation and group collective evaluation. In addition to the appropriate evaluation of the group's learning results, the teachers' pay more attention to the evaluation of students' cooperative attitudes, cooperation methods and participation levels in the learning process. More attention should be paid to the students' listening, communication and collaboration, and the outstanding performance of the group and Individuals are fully affirmed in time. The scientific evaluation system pursues a combination of multiple evaluation methods: student self-assessment, team member mutual evaluation, teacher score, and formative evaluation and final evaluation. The group cooperates and learns to "do not seek success for everyone, but seeks everyone's progress" as a realm of teaching. Therefore, teachers should pay special attention to the evaluation process. Each student should not be measured with a ruler. Teachers should give more encouragement. The vision allows students to fully experience the joy of cooperative learning and fully enjoy the joy of learning.

\section{CONCLUSIONS}

At the end of the semester and during the students' conversations, the students have already developed a strong interest in the group cooperative learning model. They have already liked the group cooperative learning, have been integrated into the group learning, and have a deep understanding and comprehensive grasp of the linear algebra course through the group learning mode. Although there are still many problems in this process, I believe this is only a matter of time. It will soon be better and fully demonstrates that "learning is active and happy, and the classroom is wonderful because of its presentation". For teachers, it is necessary to be good at guiding students. Only by continually exploring in practice can they innovate and guide students better. Now, although the group cooperative learning model we introduced in the linear algebra course has just started, it has entered the trajectory of the new teaching model. I believe that in the next few years, this new teaching model will develop very well. Let students fully experience the joy of learning in this learning atmosphere, and cultivate their ability to learn independently and think 
independently. I believe that the group cooperative learning model will be fruitful and applied to the study of more disciplines.

\section{REFERENCES}

1. Pholphuet, P., Kanyaprasith, K., Khumwong, P., \& Praphairaksit, N. (2018, January). The effect of integrating cooperative learning into $5 \mathrm{E}$ inquiry learning model on interpersonal skills of high school students. In AIP Conference Proceedings (Vol. 1923, No. 1, p. 030038). AIP Publishing.

2. Karacop, A. (2017). The Effects of Using Jigsaw Method Based on Cooperative Learning Model in the Undergraduate Science Laboratory Practices. Universal Journal of Educational Research, 5(3), 420-434.

3. Zengin, Y., \& Tatar, E. (2017). Integrating dynamic mathematics software into cooperative learning environments in mathematics. Journal of Educational Technology \& Society, 20(2), 74-88.

4. Larraz, N., Vázquez, S., \& Liesa, M. (2017). Transversal skills development through cooperative learning. Training teachers for the future. On the Horizon, 25(2), 85-95.

5. Liu, J. (2014). Some thoughts on the problem design in group teaching. Science and Education Exchange, (1), 151-151.

6. Li, X. R. Du, C. (2013). Reflections on the effectiveness of mathematics classroom design questions. Examination Weekly, 91; 75-75.

7. Sharan, Y., \& Sharan, S. (1992). Expanding cooperative learning through group investigation. New York: Teachers College Press, 1992.

8. Liu, X. (2017). Group cooperative learning in English writing of junior high schools. English on Campus, 2017(10):110-110. 